\title{
The Potential and Outcomes of Clustering in Healthcare - Expectations of Polish Health Care Providers
}

\author{
By Piotr Romaniuk* \\ Tomasz Holecki ${ }^{\dagger}$
}

In this paper we describe the results of a study conducted in Poland, which aimed at recognizing how clusters are perceived by providers of health services. The most important finding is that the current clustering potential is low, which is determined both by lack of knowledge and will among potential partners to enter the cooperation, as well as by the unfavourable legal environment, as it is perceived by the service providers. At the same time health care stakeholders are aware of the possible benefits, which might be obtained from clustering, mainly in the sphere of service provision and higher health system efficiency, both in the economic and the social dimension. Providers perceive the benefits as relevant for both local communities, and for members of clusters. Based on our findings we recommend the creation of a policy programme to support clusters consisting of legal and tax preferences, to promote cluster initiatives as well as to support for leaders of clustering to overcome a fundamental barrier to the development of cluster initiatives, which are a lack of vital leadership and centres of developing new organisational formulas in healthcare.

Keywords: Clustering, Health services, Poland, Provides' expectations

\section{Introduction}

A cluster is an organisational form of business partnership that attracts growing interests and attention among management theorists, as well as practitioners of entrepreneurship and policy makers. Porter (2000) in the classic definition describes clusters as "a geographically proximate group of interconnected companies and associated institutions in a particular field, linked by commonalities and complementarities". Bergman and Feser (1999) in turn, define clusters as "a group of business enterprises and non-business organizations for whom membership within the group are an important element of each member firm's individual competitiveness". Finally, the OECD (2001) defines clusters as a "geographic concentration of similar or complementary businesses, which dispose with active channels to provide transactions and communication, and use specialized infrastructure, markets, and services". If so defined, a cluster becomes a complex of ties binding members together in different dimensions of their activities.

${ }^{*}$ Professor, Department of Health Policy, School of Public Health, Medical University of Silesia in Katowice, Poland.

${ }^{\dagger}$ Assistant Professor, Department of Health Economics and Management, School of Public Health, Medical University of Silesia in Katowice, Poland. 
The concept of clusters is quite broad. Being built on traditional theories of location and agglomeration, it interferes into, among others, the concepts of industrial districts, centres of growth, production systems, regional innovation systems, or learning and creative regions (European Commission 2008). Although the networking method has been known for years, cluster theory made a critical change into it. In 2006, Porter identified clusters as a method of increasing the competitiveness of enterprises and regions at the same time (Sölvell 2008).

Clusters are a phenomenon that appears mainly through the bottom-up initiatives provided by the industrial entities, and they are usually formed as a result of searching for competitive advantages over the environment. They can, however, be created by clustering-oriented national policies, in such cases they are included in the catalogue of public tasks (European Commission 2006a). Mainly for this reason clusters started to grow very rapidly worldwide in the recent dozen years, with a variety of strategies to support them prepared by governments and local authorities in different countries. They are observed with interest for their contribution to market competitiveness, but also because of their active public support, that is being granted to cluster initiatives.

In Europe the national policies are additionally enmeshed in European development programmes, where the concept of clustering is involved in the catalogue of priorities listed in the strategic document "Europe 2020" as an important element of the EU economic policy. Among others issues, the document also includes the aim to develop smart, sustainable economies, based on knowledge and innovation, which should come into life with support for environment-friendly activities, prevention of social inclusion, insurance of social and territorial cohesion, and also by the reduction of the cost of doing business in Europe, promotion of clusters and improvement of the affordable access to funding. For Europe to be competitive within an intercontinental environment, and to ensure social security at least at the current level, there is a new model of business that needs to be generated. Clusters are probably one of the possible solutions, fitting into the EU policy (European Commission 2005 and 2006b).

Similarly the Communicate of the European Commission of 2008 proposed creating effective conditions for supporting the development of cluster initiatives in Europe (European Union 2011)' underlining that there is still no unified policy model on clusters, and there are significant differences in the detailed arrangements within Member States. Currently, a dominating cluster policy in the EU, is one based on the "triple helix" model, which assumes the interaction between entrepreneurs, as well as between entrepreneurs and R\&D sector representatives, accompanied by the public authorities (European Commission 2002, Etzkowitz and Leydesdorff 1995). This is also the case of Poland, where this study was conducted.

While clustering became a popular trend among classic business enterprises, it looks slightly different in health care, mainly because of the different way the health sector is perceived, due to its socially-oriented activity, but also because of a strong engagement of the public authorities in the 
organisational stimulation and financial flows in the health care system, as well as widespread expectations that it will act based on a non-for-profit rule. The health sector is often recognized for escaping the organisational formulas that are applicable on the ground of typical business markets. Nonetheless sector clusters are starting to develop rapidly, where only in Poland more than 20 such partnerships have been established in the recent few years (Hołub-Iwan 2012).

Both the growing popularity of clustering, and the specifics of the market of health services, raised the question regarding the way clusters are perceived by the health market stakeholders. There is an interesting issue referring to the adequacy of this form for the health sector, but also the one addressing possible results the clustering may bring for different stakeholders, having interest involved in the national health system. This constitutes a basic premise for conducting the presented study. The aim of our paper therefore is to present the results of the study in terms of the way clusters are perceived by providers of health services in Poland.

\section{Methods}

We used the computer-assisted web interview (CAWI) to collect data for this study, with an original questionnaire addressed to health care units of different types as a basic tool for data collection. The questionnaire consisted of 46 questions addressing the socio-economic characteristics of the administrative area the unit is operating on, the service profile of the unit, the participation in clusters and the knowledge about clustering processes. Additionally, a number of questions addressed the providers' expectations regarding participation in clusters and general clustering processes. The study was based on a representative randomised sample, with a total number of 203 units examined. The respondents were divided into groups, based on different aspects of their characteristics, such as the scope of provided activities (ambulatory care, in-patient care, laboratory services, etc.), ownership (public $v s$ non-public), or cluster membership (yes vs no). Respondents were asked about their perception of the potential of clustering in health care, barriers and opportunities for the process of setting clusters in the Polish health system, the type and areas of influence of clustering on the health system, stakeholders to be the basic beneficiaries of clustering in health care, and finally - the types of profits clusters may bring for their beneficiaries. The data was collected between September and December 2013. For the statistical analysis we used a chi $^{2}$ test. 


\section{Result}

Table 1 presents the general information about the study sample. The numbers in brackets represent the number of cluster members in a given category of units.

Table 1. General Characteristics of the Study Sample

\begin{tabular}{|c|c|c|c|c|c|}
\hline Type of Unit & Public & Non-public & Mixed & Other & Total \\
\hline Medical technologies & 0 & 0 & 1 & 0 & $\mathbf{1}$ \\
\hline Pharmacy & 1 & 9 & 1 & 2 & $\mathbf{1 3}$ \\
\hline In-patient care & $16(1)$ & 3 & 2 & 1 & $\mathbf{2 2}$ \\
\hline Ambulatory care & 7 & $68(4)$ & 5 & 12 & $\mathbf{9 2}$ \\
\hline Spa healthcare & 9 & $13(2)$ & 2 & 2 & $\mathbf{2 6}$ \\
\hline Laboratory & 4 & 6 & 0 & 0 & $\mathbf{1 0}$ \\
\hline Other & 12 & $22(4)$ & 0 & 5 & $\mathbf{3 9}$ \\
\hline Total & $\mathbf{4 9}$ & $\mathbf{1 2 1}$ & $\mathbf{1 1}$ & $\mathbf{2 2}$ & $\mathbf{2 0 3}$ \\
\hline
\end{tabular}

Source: Authors' estimations.

The dominating group in the research sample was the ambulatory care units group (92 out of 203 investigated units). The second most popular was category "other", where we must, however underline, that respondents in some cases qualified their unit to this category, although it might fit one of the remaining categories. There was only one unit specialised in medical technologies. Most of the units were non-public. Similarly to the previous case, category "other" usually did not differ from the actual ownership form of the unit from one of the remaining categories.

The Potential of Clustering in Health Care and Legal Regulations

Figure 1 presents views of health care providers on the legal regulations in Poland in context of clustering.

Figure 1. How do the Legal Regulations Favour Clusters in Health Care: All Units

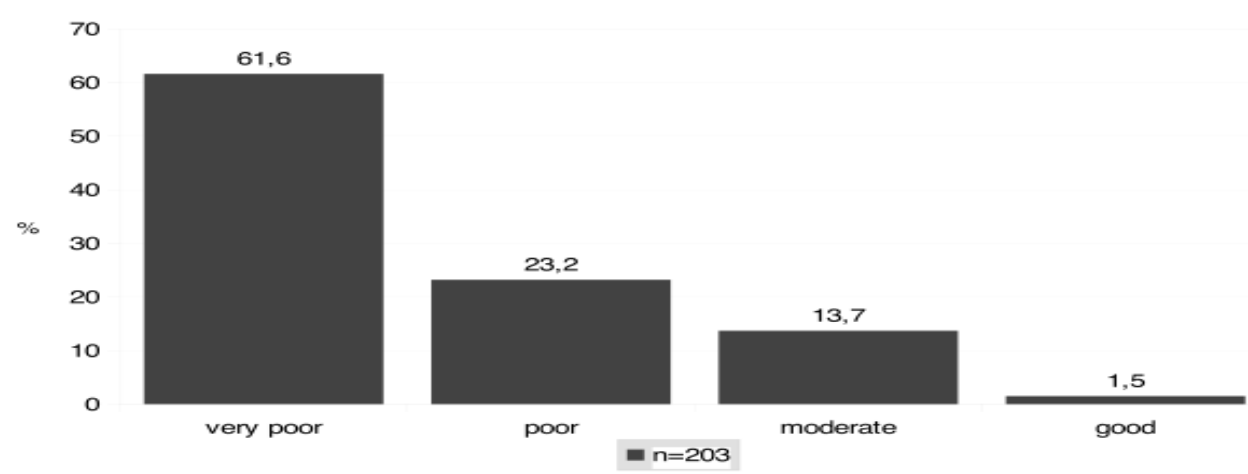

Source: Authors' estimations.

The vast majority of units assess the law as unfriendly and hostile, or at least - not supportive, to clusters in health care. Both in terms of the form of 
activity and the form of ownership, there was no difference regarding this point. Although the answers differed in details, the dominating point of view was the negative one. What is symptomatic however, is that there was a significant difference $(p=0.0010)$ when comparing units that were cluster members with non-members, where members were much more optimistic about this matter. Although none of the cluster members assessed the law as good and favourable, at the same time none of them assessed the regulations in a worst possible manner (Figure 2).

Figure 2. How does the Legal Regulations Favour Clusters in Health Care: Cluster Members and Non-Members

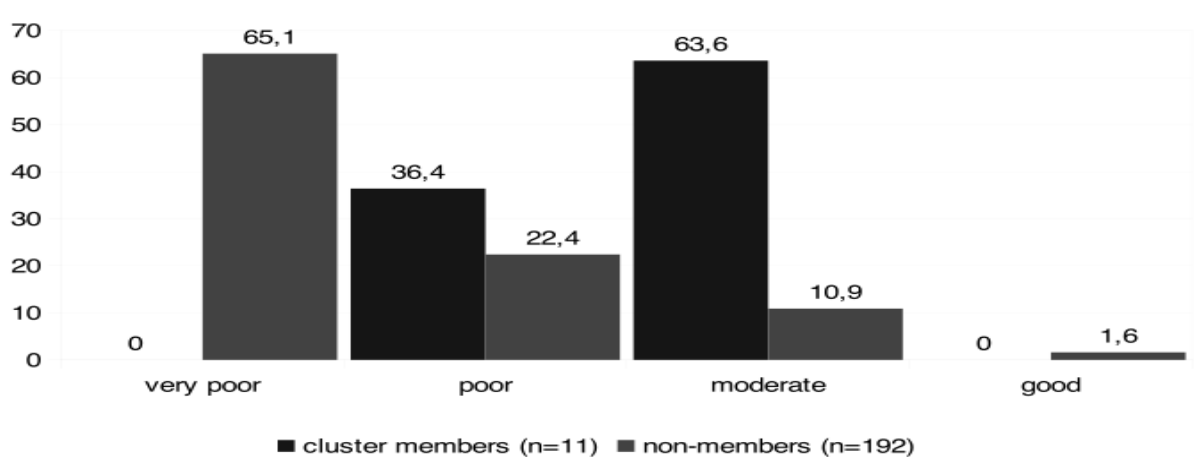

Source: Authors' estimations.

Similar is the point of view expressed by health care providers in regard to the overall potential of clustering in health care. More than $61 \%$ of all respondents assessed it as very bad, while only $7.4 \%$ in total, assessed it as good or very good (Figure 3).

Figure 3. Potential of Clustering in Health Care: All Units

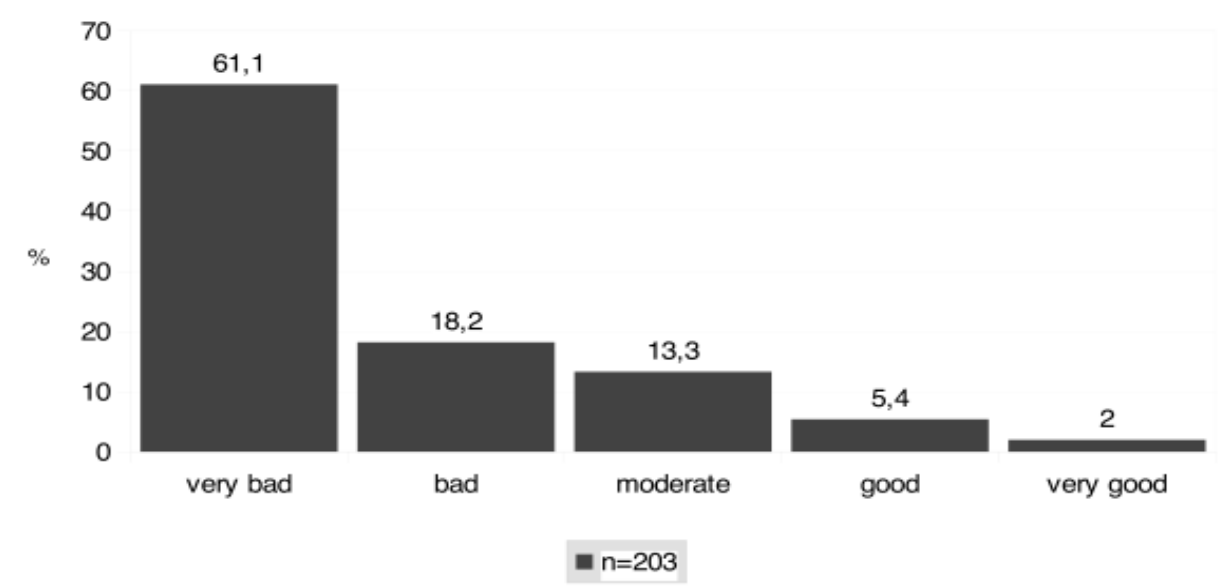

Source: Authors' estimations.

Also in this case there was no significant difference between different types of providers $(p>0.05)$. What may be surprising, when comparing units of 
different types of ownership, the public ones seem to be a bit less pessimistic. Still in every group the answer "very bad" is the most popular, but one should note that the percentage of this answer increases systematically as the share of non-public ownership increases. Still, however, there are no statistically significant differences, if to compare the share of the answer "very bad" in groups. The significance appears only when comparing the public units with the non-public ones ( $\mathrm{p}=0.0093)$ (Figure 4).

Figure 4. Potential of Clustering in Health Care: Ownership

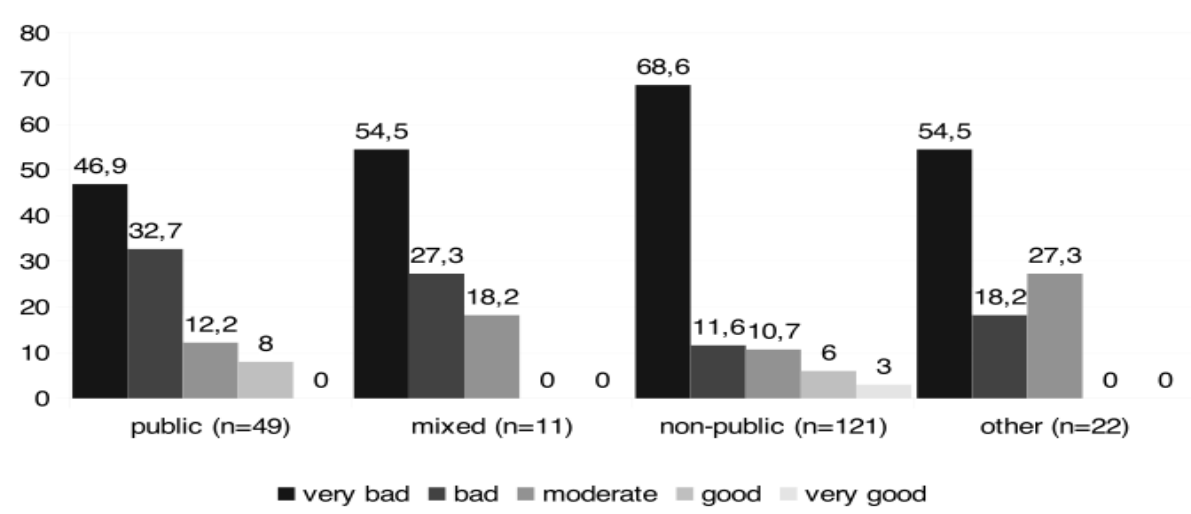

Source: Authors' estimations.

Similarly, as in the previous case, there is a difference between units that are cluster members and those, which are not. The difference on this matter is radical, in the case of the answer "very bad" ( $\mathrm{p}=0.0027)$, where members are generally much less pessimistic. Difference is significant also in the case of the answer "good" ( $\mathrm{p}=0.0010)$, while there are no significant differences in case of the "moderate" and "very good" options ( $\mathrm{p}>0.05)$ (Figure 5).

Figure 5. Potential of Clustering in Health Care: Cluster Members and NonMembers

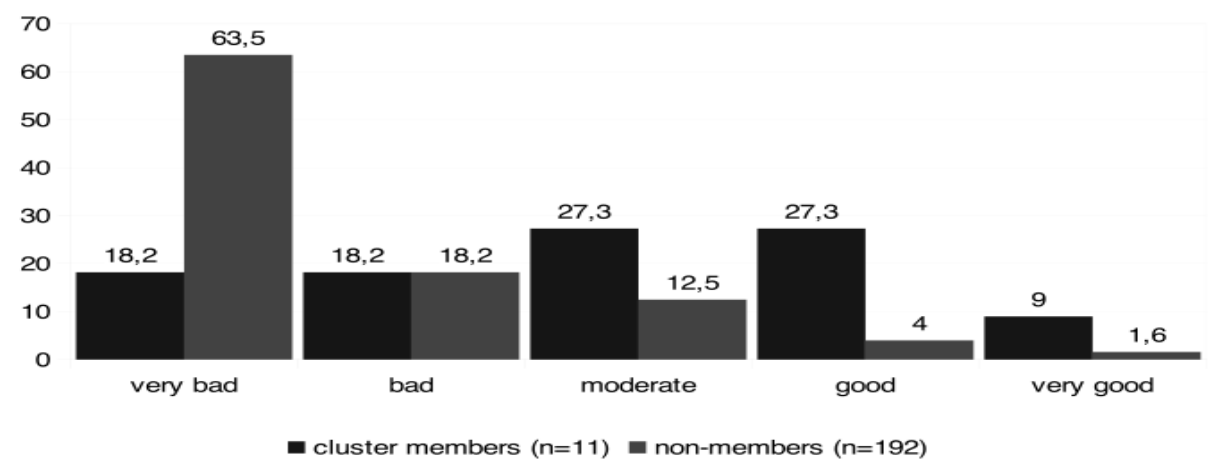

Source: Authors' estimations.

Outcomes of Clustering: Influence on Service Provision

Respondents were asked about the expected outcomes of clustering in 
health care. This part of the study was separated into several dimensions, of which one was the possible influence on service provision. As Figure 6 shows, most of the unit representatives are not able to take a firm position on this question, although those who do, mostly confirm that there is a possible influence, and only $0.5 \%$ states that there is not.

Figure 6. Influence of Clustering on Health Service Provision: All Units

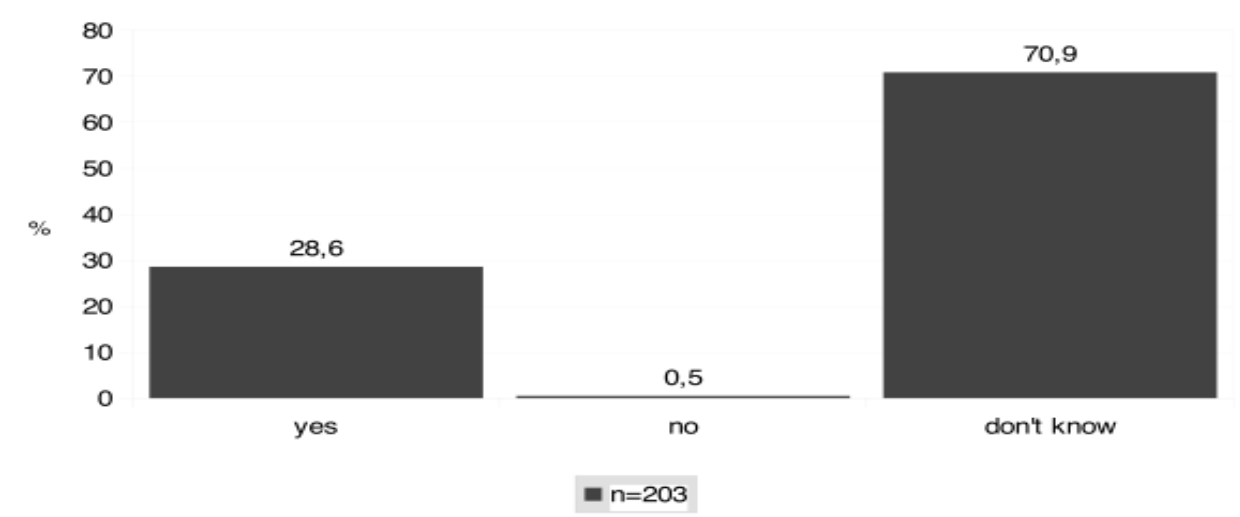

Source: Authors' estimations.

There was no difference between different types of providers and units of different ownership ( $p>0.05$ ), for that reason no result reflecting this dimension has been presented on the figure. When comparing cluster members and nonmembers, we can see members being much more confident in their opinions, with no case of indecision in this group. Difference in this case was statistically significant $(\mathrm{p}<0.0000)$ (Figure 7).

Figure 7. Influence of Clustering on Health Service Provision: Cluster Members and Non-Members

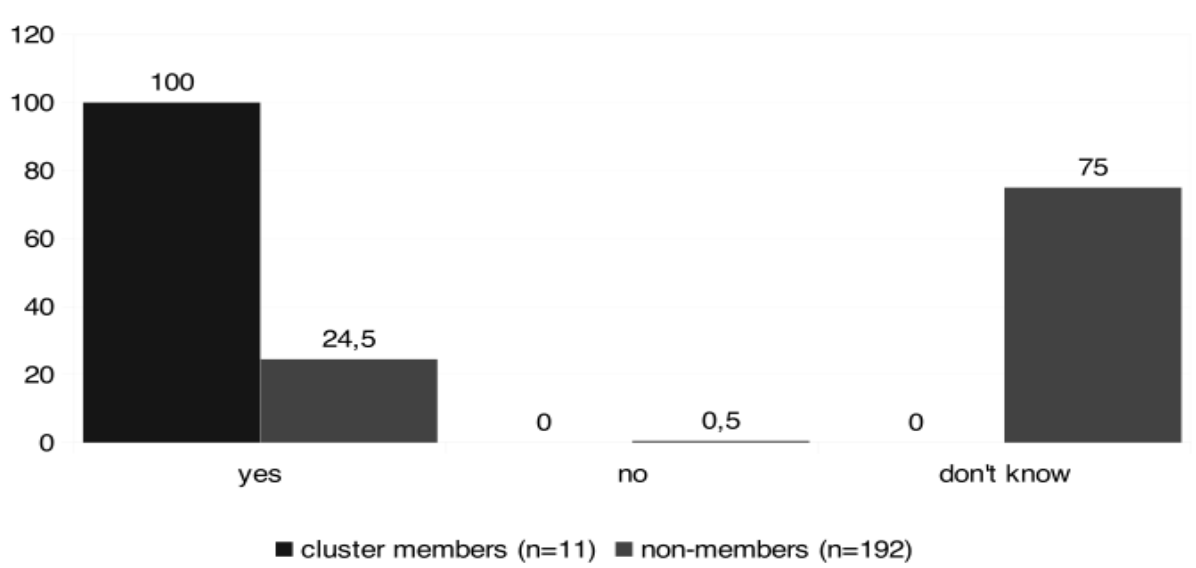

Source: Authors' estimations. 
The above question was followed with another question which addressed the ways the influence may manifest itself. Those respondents, who confirmed such an influence in the previous question $(n=58)$ were underlining mainly a better answer to health needs, as well as a better health system coordination and resource utilization. Nonetheless, only the first option was indicated significantly more often than any of the other options (Figure 8).

Figure 8. How Clusters Influence Service Provision

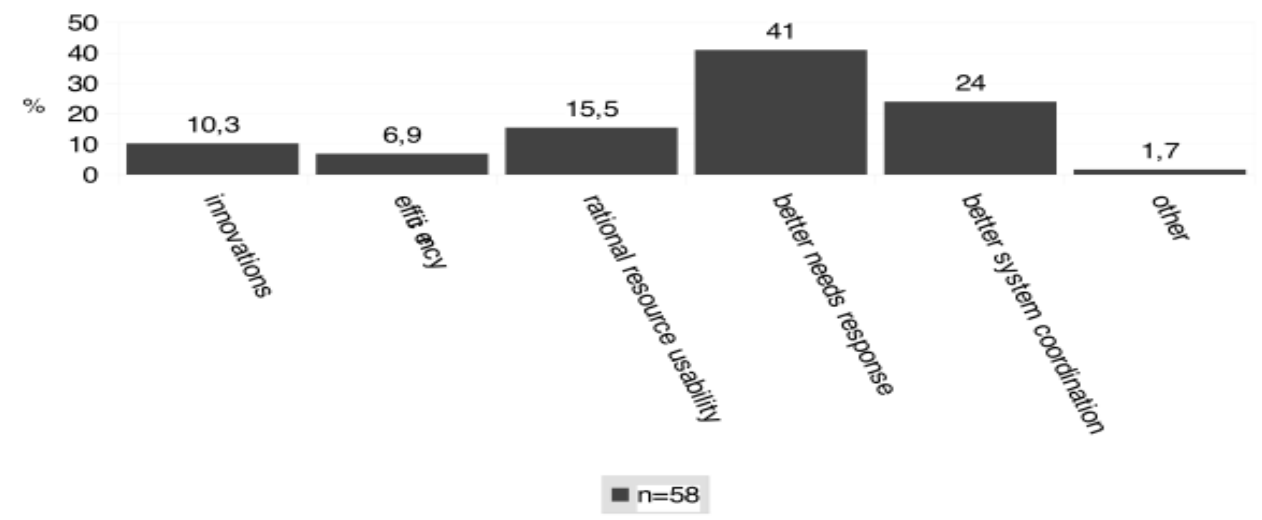

Source: Authors' estimations.

In this case we noticed differences between types of units providing medical services to patients. Both, in-patient and outpatient care providers focused mostly on health needs. Out-patient care providers more frequently indicated resource utilization and system coordination, while less frequently concentrated on financial efficiency. In case of spa service providers, system coordination has not been taken into consideration, while a "better needs response" was the most popular answer. This type of unit has also paid a significant role to innovations, which, in turn, was out of any interest for inpatient care providers. Still however, any statistical analyses in this case would not give a reliable result, since the sample sizes are too smalls (Figure 9).

Figure 9. How Clusters Influence Service Provision: Types of Unit

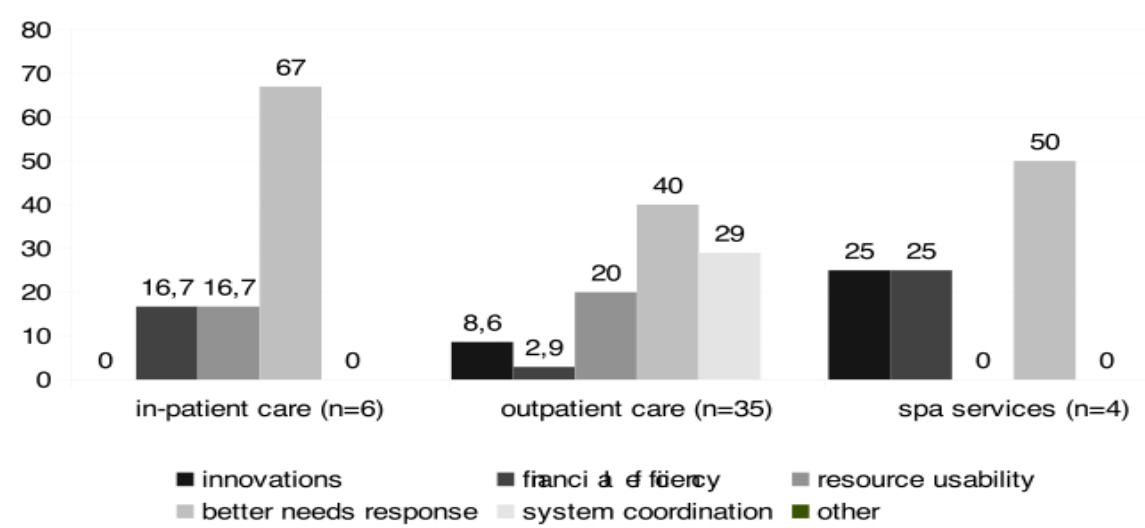

Source: Authors' estimations. 
There were no noticeable differences $(p>0.05)$ in this case between units of different ownership. Also in the case of cluster members and non-members, differences were not significant, although the members were slightly more likely to see the influence on needs recognition and system coordination, while the non-members expected financial efficiency and resource utilization as an outcome more frequently (Figure 10).

Figure 10. How Clusters Influence Service Provision: Cluster Members and Non-Members

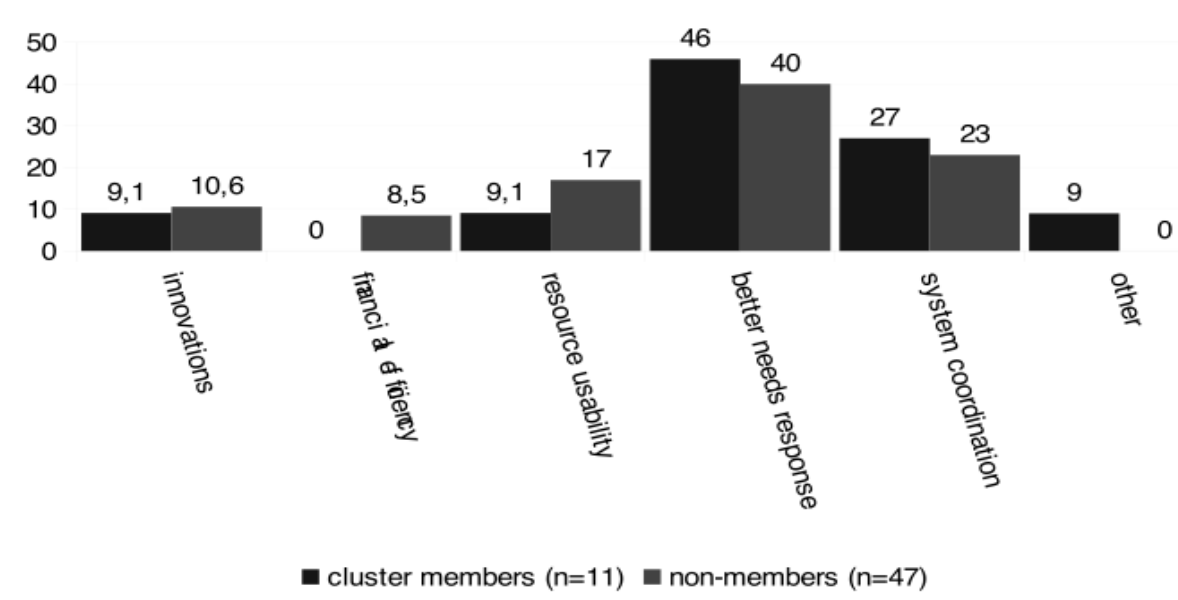

Source: Authors' estimations.

\section{Clustering in Health Care: Barriers and Opportunities}

When asked about the basic barriers for cluster creation, respondents were not able to point out any of the possible options as most important. At the same time almost half of them were not able to indicate any of the available options (Figure 11).

Figure 11. Basic Barriers of Cluster Creation (max 3 answers allowed)

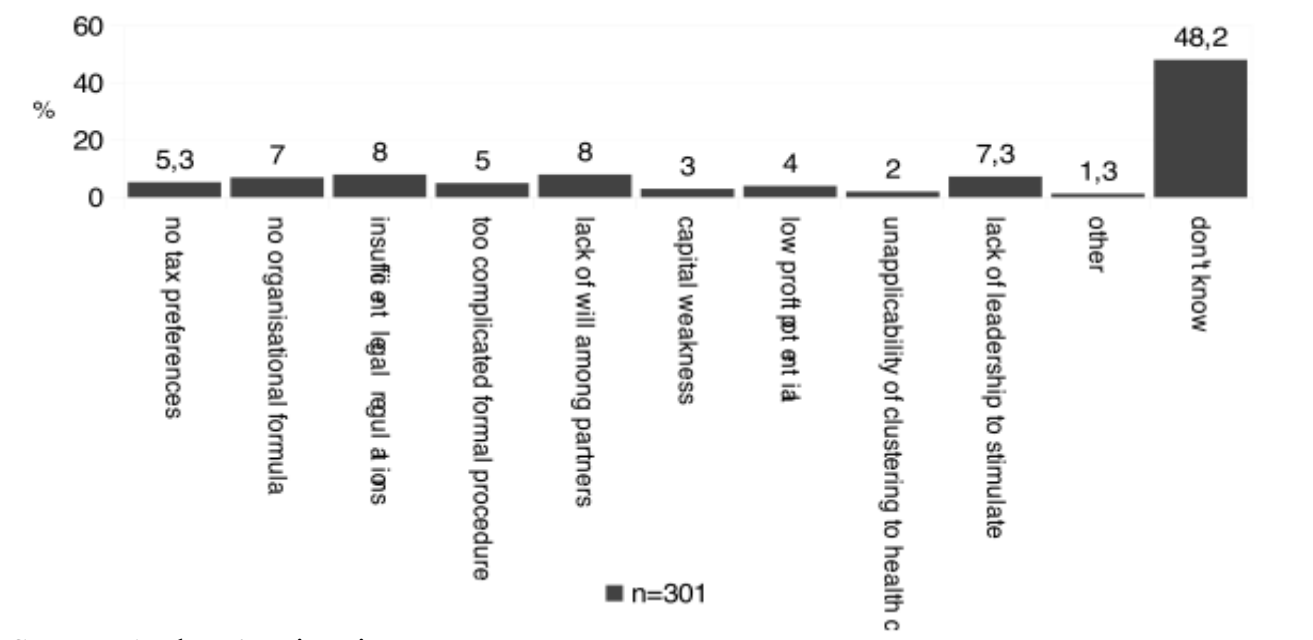

Source: Authors' estimations. 
Similarly as in previous cases, also in terms of the barriers of cluster creation there was a noticeable difference, although not statistically significant ( $>0.05$ ) between units being cluster members and those, which are not. Among cluster members there are three options that are more frequently indicated visibly. Namely, as the basic barriers those units indicated the insufficient tax regulations, which is an external factor that make clustering a project of hardly perceptible profitability for partners. The remaining two factors are the internal ones, and they both touch the area of cooperation. Cluster members have underlined the lack of will to enter the cooperation among the potential partners, as well as the lack of leaders to stimulate the process. We can presume that the second of the three factors is at least partly a consequence of the remaining two, although the general social culture features may also play a role (Figure 12).

Figure 12. Basic Barriers of Cluster Creation: Cluster Members and NonMembers (max 3 answers allowed)

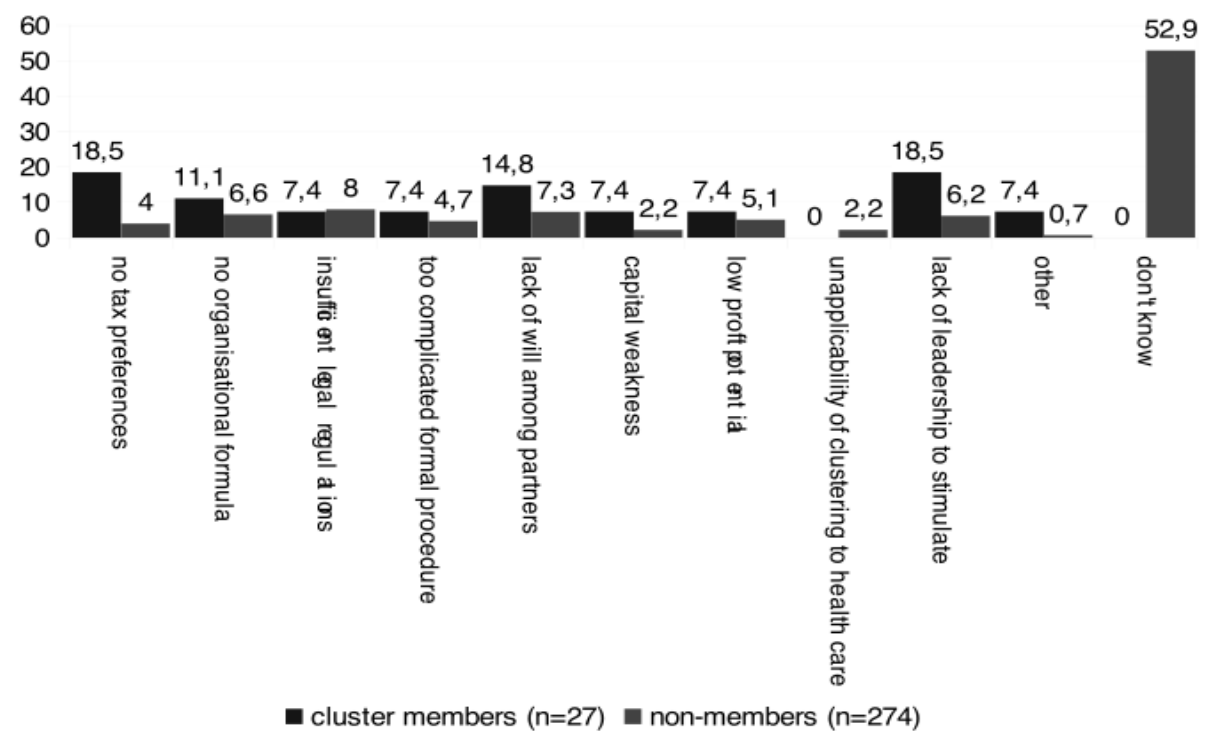

Source: Authors' estimations.

The situation in the case of the basic barriers of cluster growth was similar. In general there was not a single factor to be highlighted by the respondents as the most important. Nearly half of the units had no knowledge about the barriers (Figure 13). Cluster members were, however, more conclusive in their opinions. Similarly as in the case of cluster creation, the insufficient tax preferences were indicated as the most important barrier. Nonetheless, the second most popular answer was different than in the previous cases, as the insufficient legal regulations appeared as the identified barrier. The rest of the available options did not clearly attract differing in their scale from the remaining ones. We can conclude therefore, that in opinion of the cluster members external factors are crucial when it comes to the impact on the functioning of already existing clusters (Figure 14). 
Figure 13. Basic Barriers of Cluster Grow (max 3 answers allowed)

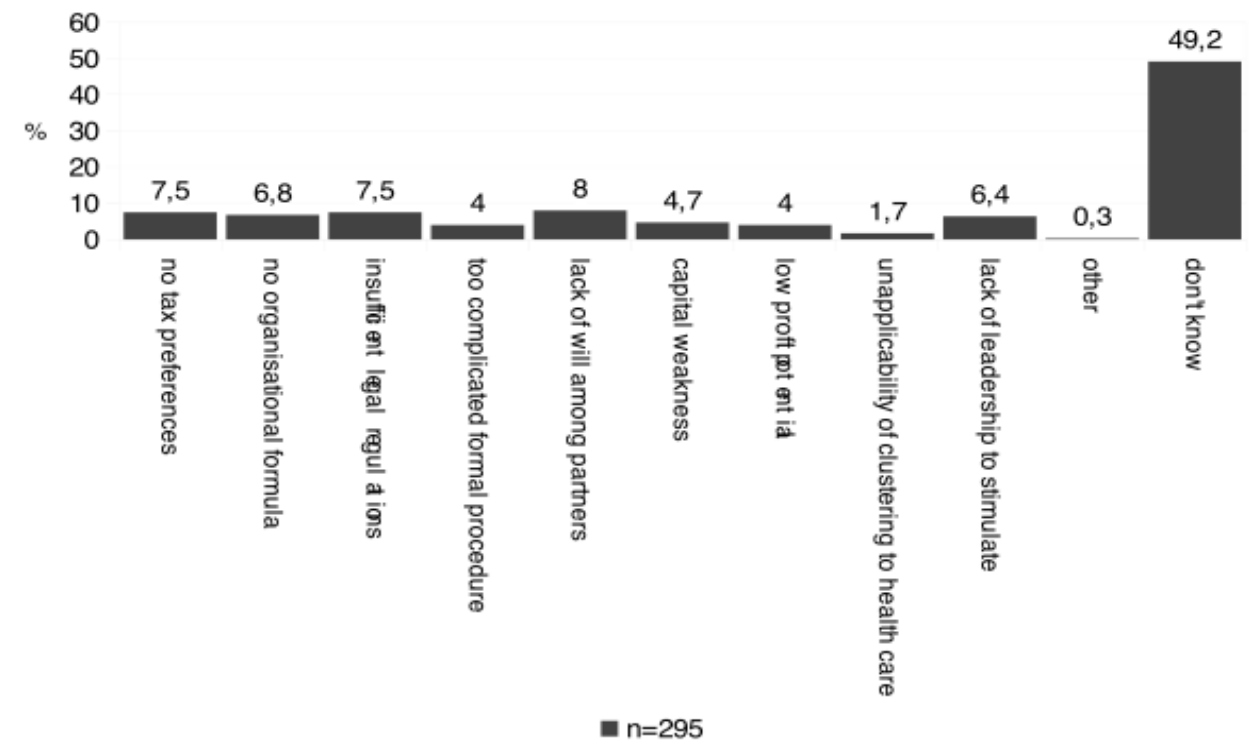

Source: Authors' estimations.

Figure 14. Basic Barriers of Cluster Grow: Cluster Members and NonMembers (max 3 answers allowed)

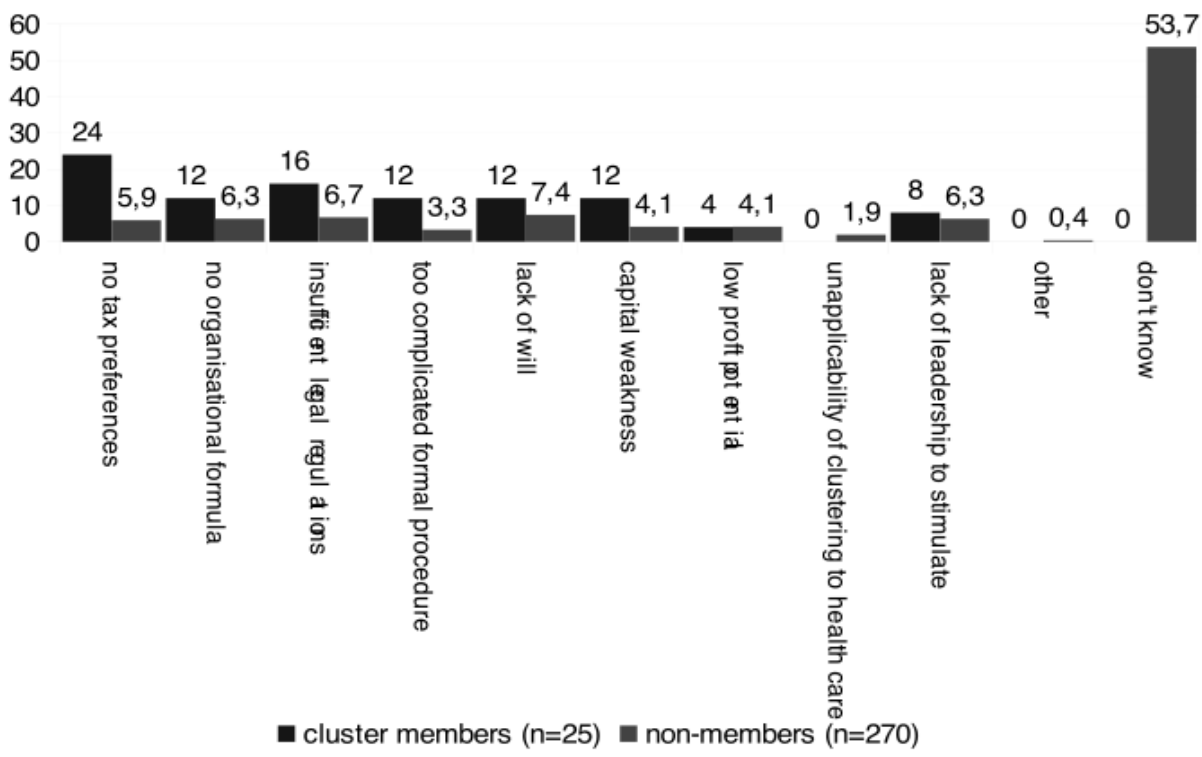

Source: Authors' estimations.

There was a huge difference in the perception of the factors determining cluster success between cluster members and non-members. While in the second group mainly the factors of axiological nature (trust) followed by the state's support were underlined, cluster members concentrated more on the rational calculation pushing members to give priority to the commonality of 
aims over internal competition. Cluster members were also more likely to see the state support as relevant, however with no statistically significant difference in this case $(\mathrm{p}=0.7173)$, as well as the way internal relations were configured, which should be interpreted more in a formal way, not one based on values (Figure 15).

Figure 15. Main Determinants of Cluster Success: Cluster Members and NonMembers (max 3 answers allowed)

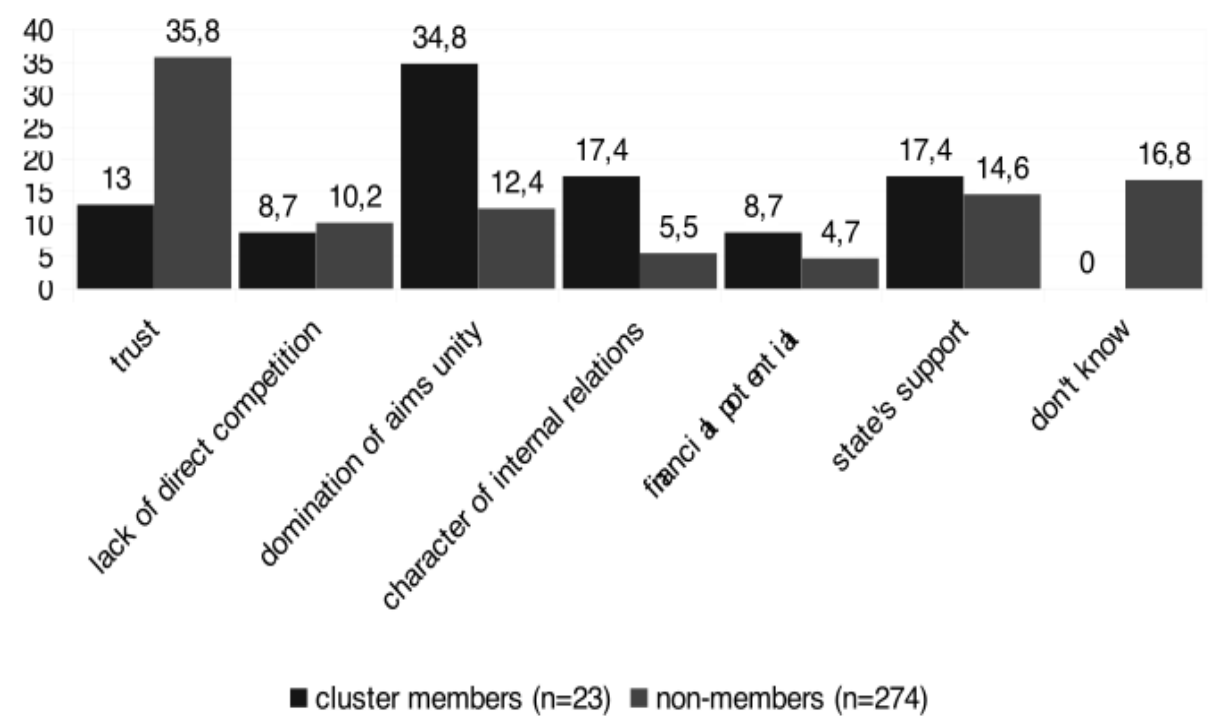

Source: Authors' estimations.

\section{Clustering in Health Care: Benefits}

Quite interesting is the perception of basic cluster beneficiaries, particularly when it comes to differences in the perception between cluster members and non-members. While in the second group most of the respondents could not identify any of the entity or body to gain benefits of clustering, those who expressed opinion, perceived the local community as the basic beneficiary, and the health care providers as the second group. Those answers seem to be somewhat divergent with the opinions in previous areas, showing a potentially high usability of clustering both for the social environment the cluster is acting in, as well as the health care units themselves. Quite similar is the point of view of cluster members, who state that both those groups of bodies may benefit in a similar scale. Additionally cluster members suggested that all the members may gain profit, not only health care providers. Concentration on providers is understandable, keeping in mind that this is the group being asked in this study. If to expand the interpretation of those responses, we can conclude that cluster members see both society and the cluster itself as a way to gain profit from this formula in a comparable scale (Figure 16). 
Figure 16. Who is the Main Beneficiary of Clustering: Cluster Members and Non-Members (max 3 answers allowed)

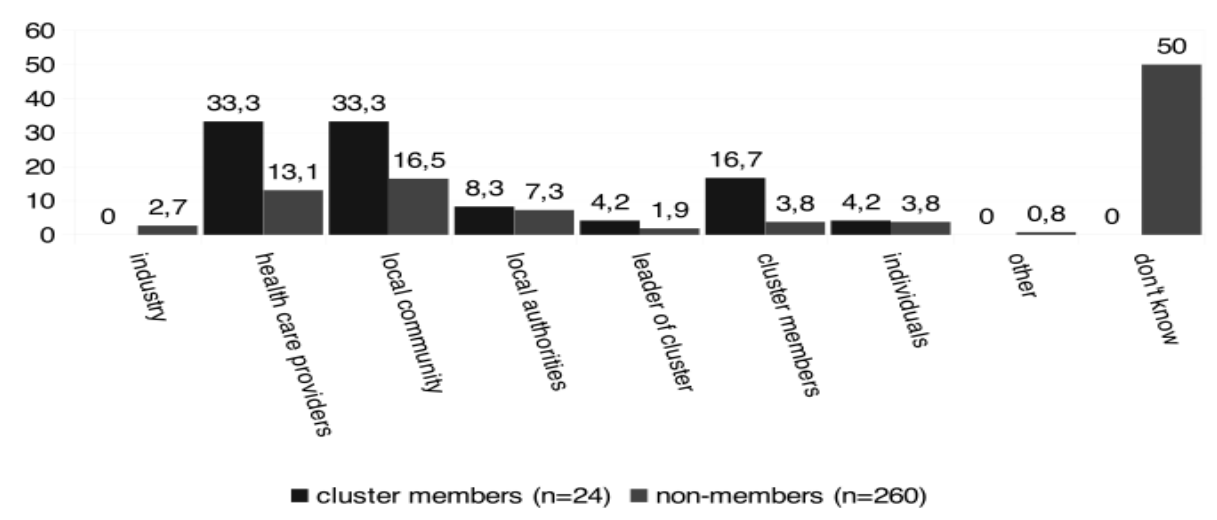

Source: Authors' estimations.

The final question respondents were asked about the kind of profits they can obtain from the membership in a partnership network. Similarly to the previous cases, most of them could not indicate even a single answer, while the rest of the respondents were not oriented in their responses unambiguously. This is both the case of cluster members and non-members, which can be interpreted in two ways. The first interpretation is that the respondents do not have any clear vision about what clustering may bring to its members. The opposite interpretation in turn will be that there is a sustainable and wide package of profits that can affect units in different dimensions of their activity. What is noticeable however, non-members are more likely to expect noneconomic profits, while cluster members concentrate rather on the financial and market dimensions, while marking the market efficiency most frequently. In both cases however, the most popular answer did not appear statistically significant more frequently than the others ( $p>0.05)$ (Figure 17).

Figure 17. What Kind of Profits can be Obtained from Cluster Membership: Cluster Members and Non-Members (max 3 answers allowed)

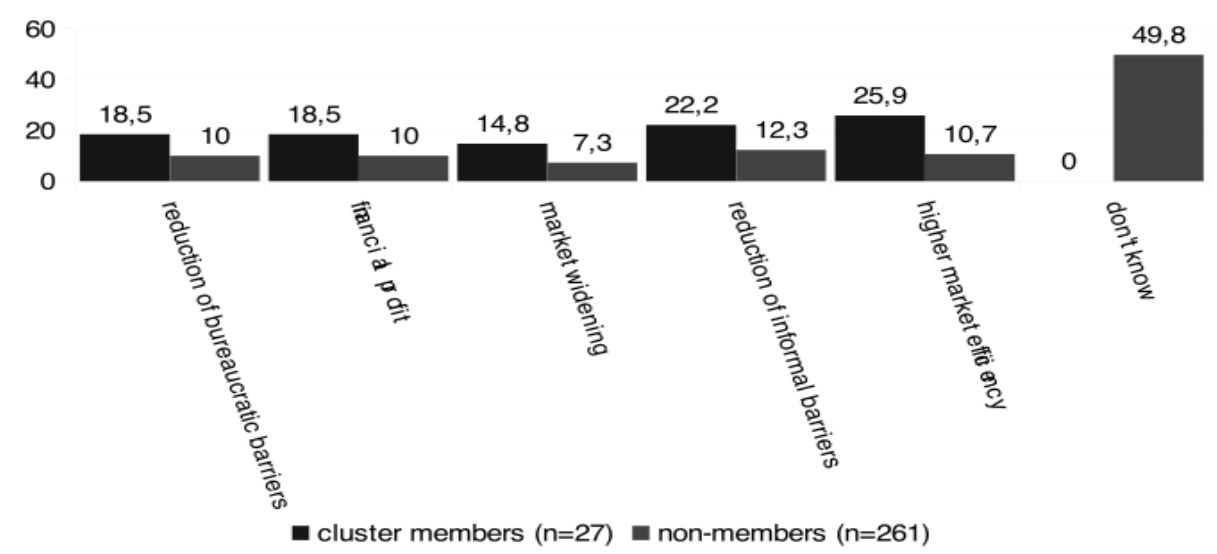

Source: Authors' estimations. 


\section{Discussion and Conclusions}

The results of our study allow us to draw some key conclusions. Firstly, the current clustering potential can be assessed as low. So suggest the opinions expressed by the establishments providing health services. Low is the potential evaluated as itself, and defined by the factors that determine it, i.e., the legal environment and the economy, which are described as unfavourable. The fact that such, and not another, is the way clusters are assessed, is not necessarily a precise reflection of the real state of things, as evidenced by the perception of the sphere by the entities already being members of clusters. Their pessimism is noticeably lower, which undoubtedly should be seen as a positive sign of the lack of justification for the concerns indicated by most of the respondents. The discrepancy of views however does not detract from the fact, that actual barriers limiting the possibility of the clustering progress do exist, whereby, in opposition to the dominant opinion, these barriers are not entirely the external ones, that arise of system and legal conditions. Similarly they are not caused by structural factors, like, for example, the inadequacy of the cluster model for the healthcare industry, or the lack of a clear vision of the organizational cluster formula for this sector. The actual barriers are:

$\checkmark$ The perception of providers, whose belief in the low clustering potential in health care, even if considered as unfounded, without a doubt can be a factor that stimulates their behaviour, or rather in this case - to refrain from behaviours or actions aimed at the formation of cluster networks, or accession to such. This conclusion arises directly from the responses regarding clustering potential and legal conditions of the process. It sounds even stronger, when confirmed by the opinions expressed by members of the existing clusters, relating real barriers to the formation and development of such initiatives. Among the key barriers, the lack of willingness of potential members, as well as the lack of a strong leader, who would stimulate this process, are quite clearly exposed.

$\checkmark$ The lack of knowledge regarding what clusters are, and what benefits may be derived from this formula. This conclusion, in turn, is supported by three observations described in the above part of the article. First, in most cases there is a noticeable and clear divergence of answers between entities non-members of a cluster and those, that already participate in such partnership networks. Second, the answers given by service providers in relation to the factors associated with cluster operations, or relating to the effects of clustering, are clearly scattered, which may suggest a certain randomness of answers. They do not reflect, at the same time, an actual vision or view on the questioned problem. Thirdly, it is impossible not to notice the overwhelming dominance of the "I do not know" answer, in the 
case of the majority of questions asked. This undeniably proofs that for the entities operating within the health system, clusters are an enigmatic and unrecognised idea. It should be noted that this conclusion applies to all sectors of the health system - both in terms of the ownership formulas, level of care, and the nature of provided services. With the exception of a few cases, responses by providers qualified to various groups remained vague in a similar extent.

That low clustering potential stands in a fairly clear opposition to the benefits this process can bring. Respondents very unequivocally emphasize that this formula can be applied in health care, thereby affecting the provision of health services and - what is more important - positively influencing it. A positive result within this dimension can have both systemic (improved financial and organizational efficiency), and social (better health needs recognition and answer to them) reflection. Of considerable importance is the fact, that potential benefits are perceived as relevant for both the local communities, and for members of clusters. This shows the multidimensionality of the clustering process, with its possible references to both the public sphere and the particularistic one. In a way therefore, indispensably the above conclusions lead to the final reflection arising from our study: the process of clustering in health care requires support and external stimulation, which should be understood in the first place as provided by the public institutions. This results from both the respondents views, in particular the current cluster members, as well as from the combination of circumstances, as described above. The group that should be interested in clustering will probably not be able to achieve the desired degree of dynamics based on their own initiative. Public involvement is justified by the nature of health care as well. While remaining in the area of social sensitivity, to a large extent it depends on public stimulation and coordination. In addition, as shown in the existing analyses (Osborne 2000, Nikolic and Maikisch 2006), the formula of public-private symbiosis, organizational and financial share of responsibility, is supremely advantageous from the point of view of expected health outcomes and efficiency.

Among the recommended ways public authorities should support clustering, the following should be particularly suggested:

The creation of a system of legal and tax preference for cluster initiatives. Even if we assume that the rules already in operation are adequate in terms of capacity, and generate benefits for clusters, such actions should be considered in terms of the promotion of cluster initiatives, that stimulate the behaviour of entities within the health system, and that increase their awareness of the existing possibilities in this regard.

$\checkmark$ Organizational support in terms of know-how available for the particular entities that might take the role of leaders of clustering, 
and then transfer acquired skills and knowledge to other entities, through the created and running cluster initiatives. The deficit of leaders is one of the fundamental weak points of the health care sector, as identified in our study. It can be explained by both the lack of a culture of cooperation characterizing Polish society (Letki and Evans 2005, Kochanowicz 2004), and by the weaknesses of the healthcare sector, where a large proportion of organisations focus on current problems arising from the balancing on the brink of financial collapse, rather than making strategic actions for future benefits. As these factors to some extent are dependent on the State's health policy, the more reasonable it becomes to postulate above stimulus action, including those using legal and fiscal instruments.

\section{Acknowledgements}

The study is a part of the research project "Regional health care cluster", which has been financed by the Polish National Science Centre, based on the decision No. DEC-2011/03/B/HS4/04181.

\section{References}

Bergman EM, Feser EJ (1999) Industrial and Regional Clusters: Concepts and Comparative Applications. Web Book in Regional Science. Ch. 2. Regional Research Institute. Morgantown: West Virginia University.

Etzkowitz H, Leydesdorff L (1995) The Triple Helix: University-IndustryGovernment Relations: A Laboratory for Knowledge Based Economic Development. EASST Review 14: 14-19.

European Commission (2002) Industrial Policy in an Enlarged Europe. Brussels: European Commission.

European Commission (2005) More Research and Innovation - Investing for Growth and Employment: A Common Aproach. Brussels: European Commission.

European Commission (2006a) Implementing the Community Lisabon Programe: Fostering Entrepreneurial Mindsets through Education and Learning. Brussels: European Commission.

European Commission (2006b) Putting Knowledge into Practice: A Broad-Based Innovation Strategy for the EU. Brussels: European Commission.

European Commission (2008a) The Concept of Clusters and Cluster Policies and their Role for Competitiveness and Innovation: Main Statistical Results and Lessons Learned. Brussels: European Commission.

European Commission (2008b) The European Cluster Memorandum. Promoting European Innovation through Clusters: An Agenda for Policy Action. Centre for Strategy and Competitiveness. Stockholm School of Economics. Stockholm: Europe INNOVA Initiative of the European Commission.

European Union (2011) EU Communicate EUROPA 2020. A Strategy for Smart, Sustainable and Inclusive Growth. Brussels: European Union.

Hołub-Iwan J (2012) Benchmarking Klastrów w Polsce - Edycja 2012 [Benchmarking 
of Clusters in Poland - 2012 Edition]. Warsaw: PARP. [In Polish]

Kochanowicz J (2004) Trust, Confidence and Social Capital in Poland: A Historical Perspective. In: Markov I (ed.) Trust and Democratic Transition in PostCommunist Europe. Oxford: Oxford University Press, 63-84.

Letki N, Evans G (2005) Endogenizing Social Trust: Democratization in East-Central Europe. British Journal of Political Science 3(35): 515-529.

Nikolic IA, Maikisch H (2006) Public-Private Partnerships and Collaboration in the Health Sector. An Overview with Case Studies from Recent European Experience. The International Bank for Reconstruction and Development. Washington: The World Bank.

OECD (2001) Innovative Clusters, Drivers of National Innovation System. Paris: OECD Proceedings.

Osborne SP (eds) (2000) Public-Private Partneships. Theory and Practice in International Perspective. London, New York: Routledge.

Porter ME (2000) Location, Competition and economic development: local clusters in a global economy. Economic Development Quarterly 14: 15-34.

Sölvell O (2008) Clusters: Balancing Evolutionary and Constructive Forces. Stockholm: Ivory Tower Publishers. 02 July 2014]. 
